\title{
Use of Bone Marrow Aspirate Concentrate (BMAC) Associated with Hyperbaric Oxygenation Therapy in Maxillary Appositional Bone Reconstruction. A Randomized Clinical Trial
}

\author{
Antonio Carlos Aloise ${ }^{1}$, Paulo Pasquali ${ }^{2}$, Marcelo Sperandio ${ }^{1}$, \\ Luis Guilherme Scavone de Macedo ${ }^{1}$, Marcelo Lucchesi Teixeira ${ }^{1}{ }^{\mathbb{D}}$, André Antonio Pelegrine ${ }^{1}$ \\ and José Luis Calvo-Guirado ${ }^{3, *(D)}$ \\ 1 Faculdade São Leopoldo Mandic, Instituto de Pesquisas São Leopoldo Mandic, Campinas 13000-000, Brazil; \\ aca.orto@uol.com.br (A.C.A.); marcelo.sperandio@slmandic.edu.br (M.S.); \\ drluismacedo@yahoo.com.br (L.G.S.d.M.); marceloltx@gmail.com (M.L.T.); \\ andre.pelegrine@slmandic.edu.br (A.A.P.) \\ 2 Private Practice, Erechim 99700-000, Brazil; paulo@paulopasquali.com.br \\ 3 Department of Oral and Implant Surgery, Faculty of Health Sciences, Universidad Católica San Antonio de \\ Murcia, 30107 Guadalupe, Spain \\ * Correspondence: jlcalvo@ucam.edu; Tel.: +34-968-268353
}

Received: 16 September 2018; Accepted: 20 October 2018; Published: 22 October 2018

\begin{abstract}
Objectives: The objective of this study was to evaluate bone reconstruction using xenograft alone and associated with bone marrow aspirate concentrate (BMAC) and hyperbaric oxygen therapy. Material and Methods: Twenty-four maxillary edentulous patients were randomly assigned into three groups: Control group (CG) — xenograft bone alone ( $n=8)$; Group 1 (G1)—xenogeneic bone block combined with BMAC $(n=8)$, and Group $2(\mathrm{G} 2)$ - xenogeneic bone block combined with BMAC and hyperbaric oxygenation $(n=8)$. Bone biopsies were harvested 6 months after grafting. Vital Mineralized Tissue (VMT), Non-vital Mineralized Tissue (NVMT), and Non-Mineralized Tissue (NMT) were measured. Computed tomography was also performed on three occasions T0 (preoperative), T4 (4 months postoperative), and T8 (8 months postoperative). The difference between $\mathrm{T} 4$ and $\mathrm{T} 8$ values with respect to $\mathrm{T} 0$ was used to determine the thickness level gain after 4 and 8 months, respectively. Results: The tomographic evaluation did not show significant differences between the groups either at 4 or at the 8 months postoperatively. Regarding the histomorphometric analysis, CG had the lowest percentages of VMT (36.58 $\pm 9.56 \%)$, whereas G1 and G2 had similar results $(55.64 \pm 2.83 \%$ and $55.30 \pm 1.41 \%$, respectively). Concerning NMT and NVMT levels, the opposite was observed, with CG levels of $51.21 \pm 11.54 \%$ and $11.16 \pm 2.37 \%$, G1 of $39.76 \pm 11.48 \%$ and $3.65 \pm 0.87 \%$, and G2 of $40.3 \pm 11.48 \%$ and $4.10 \pm 0.87 \%$, respectively. Conclusions: The use of bone block xenograft associated with BMAC resulted in a significant increase of bone neoformation when compared to the xenograft alone, though hyperbaric oxygenation did not enhance the results.
\end{abstract}

Keywords: maxilla; bone marrow; hyperbaric oxygenation; bone xenograft

\section{Introduction}

Autologous bone grafting is regarded as the gold standard for reconstruction of bony defects. The use of autologous bone grafts is a safe option to restore bone volume for implant supported dental rehabilitations, with the added benefit provided by the osteogenic (by the osteoprogenitor cells), osteoinductive (by the molecules that can induce osteogenic differentiations of local stem cells), 
and osteoconductive (by the scaffold that permits bone apposition) stimuli inherent of such tissues. However, there are some issues that must be stated concerning this approach, such as morbidity of the donor site, limited bone supply, and loss of bone volume during healing. Other options such as synthetic, allograft, and xenogenic bone have also been used for bone regeneration purposes [1]. In this field, the xenogenic equine block biomaterial is a reasonable alternative to autologous grafting, as it has been demonstrated to generate adequate levels of hard tissue gain in reconstructions of the atrophic maxilla [2].

In recent years, an increasing interest in the use of bone marrow stem cells for bone regeneration has been observed, since in vitro and in vivo experiments have shown highly promising results [3]. In addition to being able to give rise to blood cells, bone marrow may have the potential to induce undifferentiated cells to differentiate into a variety of tissues, including bone and cartilage [4]. In this scope, nowadays nanoscience is producing novel substitutes that could imitate the extra cellular matrix conditions of these tissues [5].

The lack of cellularity observed in bone substitute biomaterials has been fuelling research into the field of tissue engineering aiming at combining autologous osteogenic cells with osteoconductive structures. In this context, bone marrow is one of the most widely used sources of autologous cells. Bone marrow contains a series of cells with affinity for bone regeneration, such as undifferentiated mesenchymal cells [6,7]. In addition, they also feature an angiogenic potential associated with vascular endothelial growth factor [8], a highly desirable property for graft integration [9]. The process to obtain a bone marrow aspirate concentrate (BMAC) increases the density of potentially osteogenic cells within the bone graft, which has been explored in research to increase the osteoinductive potential of fresh bone marrow cells [10]. Furthermore, puncture aspiration to harvest bone marrow cells is relatively easier than harvesting autologous bone for grafting from the same donor site [11]. Hernigou et al. (2014) [12] compared the donor area complications when using bone marrow cells obtained by aspiration from the iliac crest with the classical bone graft harvested from the iliac crest and verified that complications with bone marrow aspiration was ten times less, and the complications were clearly less severe. Therefore, BMAC has being considered a technique that can enhance the potential of bone grafts procedures with minimal morbidity.

Another technique that is being related to an improvement in bone regeneration without the morbidity related to the autogenous bone graft is the use of rh-BMP. However, despite the potential to substitute the usage of autogenous bone graft in challenging situations such as clefts of the anterior maxilla and reconstruction of large defects after tumor resection or osteonecrosis treatment, the use of rh-BMP is also related to some issues (e.g., inconsistent or poor-quality bone formation, alteration of osteoblast/osteoclast balance, and adverse facial edema) [13]. Therefore, some researchers, instead of using non-physiological levels of growth factors, are focusing their studies in the autologous use of bone marrow cells for bone regeneration purposes, which is the main goal of the present study.

Hyperbaric oxygen therapy consists in exposing the patient to $100 \%$ oxygen under high pressure. This therapy is based on two physical laws and some biochemical processes that explain its mechanism of action. The first, Henry's law, according to which the amount of gas dissolved in a liquid (in this case, oxygen in plasma) increases with the pressure exerted by this gas on that liquid. The second, Boyle-Mariotti's law, according to which the space occupied by a certain volume of gas will decrease as pressure increases, i.e., gas volume shrinks under high pressure, whereas it expands with low pressure [14]. The mechanism of action of hyperbaric oxygen therapy is the result of a combination of factors. Leukocytes under hypoxia struggle to phagocytize bacteria, which is reversed when oxygen tension is raised again. In addition, synthesis of collagen by fibroblasts increases with an enhanced availability of oxygen. Postoperative hyperbaric oxygenation in bone grafting procedures has also been associated with improvements in bone healing [15].

Therefore, it can be speculated that using both BMAC and hyperbaric oxygen in bone augmentation procedures could maximize the regenerative results, which might have clinical repercussions in the bone reconstruction field. Considering the aforementioned context, the aim 
of this study was to evaluate the effect of bone marrow aspirate concentrate combined with xenografts on the treatment of the atrophic maxilla in patients submitted to hyperbaric oxygenation.

\section{Materials and Methods}

The surgical protocol for this study was analyzed and approved by the São Leopoldo Mandic Dental School Ethics Committee (number 838.635/14).

The clinical procedures were undertaken with the understanding and written consent of each patient and in full accordance with the ethical principles of the World Medical Association Declaration of Helsinki (2013). Furthermore, the study was conducted in compliance with the Consolidated Standards of Reporting Trials (CONSORT) statement, where applicable. Pregnant, diabetic, or immunocompromised patients, as well as smokers and patients under any sort of medication that could interfere with the surgical protocol or with bone metabolism were excluded from the study. After applying these exclusion criteria, twenty-four maxillary edentulous patients with an a 2 to $3 \mathrm{~mm}$ anterior alveolar ridge thickness were selected from the outpatient dental clinic at Santa Monica Medical Center (Erechim, Brazil), all of whom agreed to participate in this study and signed an informed consent form prior to initiating treatment. All patients required a fixed rehabilitation (i.e., implants and a Branemark's protocol rehabilitation).

The patients were assigned into three groups: Control group (CG) - xenogeneic bone blocks only $(n=8)$; Group 1 (G1), in which patients received a xenograft combined with BMAC $(n=8)$; Group 2 (G2) - patients receiving xenogeneic bone blocks associated to BMAC and hyperbaric oxygenation $(n=8)$. In all patients, collagen membranes were positioned over the xenogeneic bone blocks following the principles of guided bone regeneration (GBR).

\subsection{Bone Marrow Aspirate Concentrate (BMAC)}

In an outpatient setting, $30 \mathrm{~mL}$ of bone marrow was harvested from the patients via puncture aspiration of the iliac bone using an $11 \mathrm{G}$ cannula (Terumo ${ }^{\circledR}$, São Paulo, SP, Brazil) under local anesthesia ( $2 \%$ xylocaine without vasoconstrictor) (Figure 1$)$.

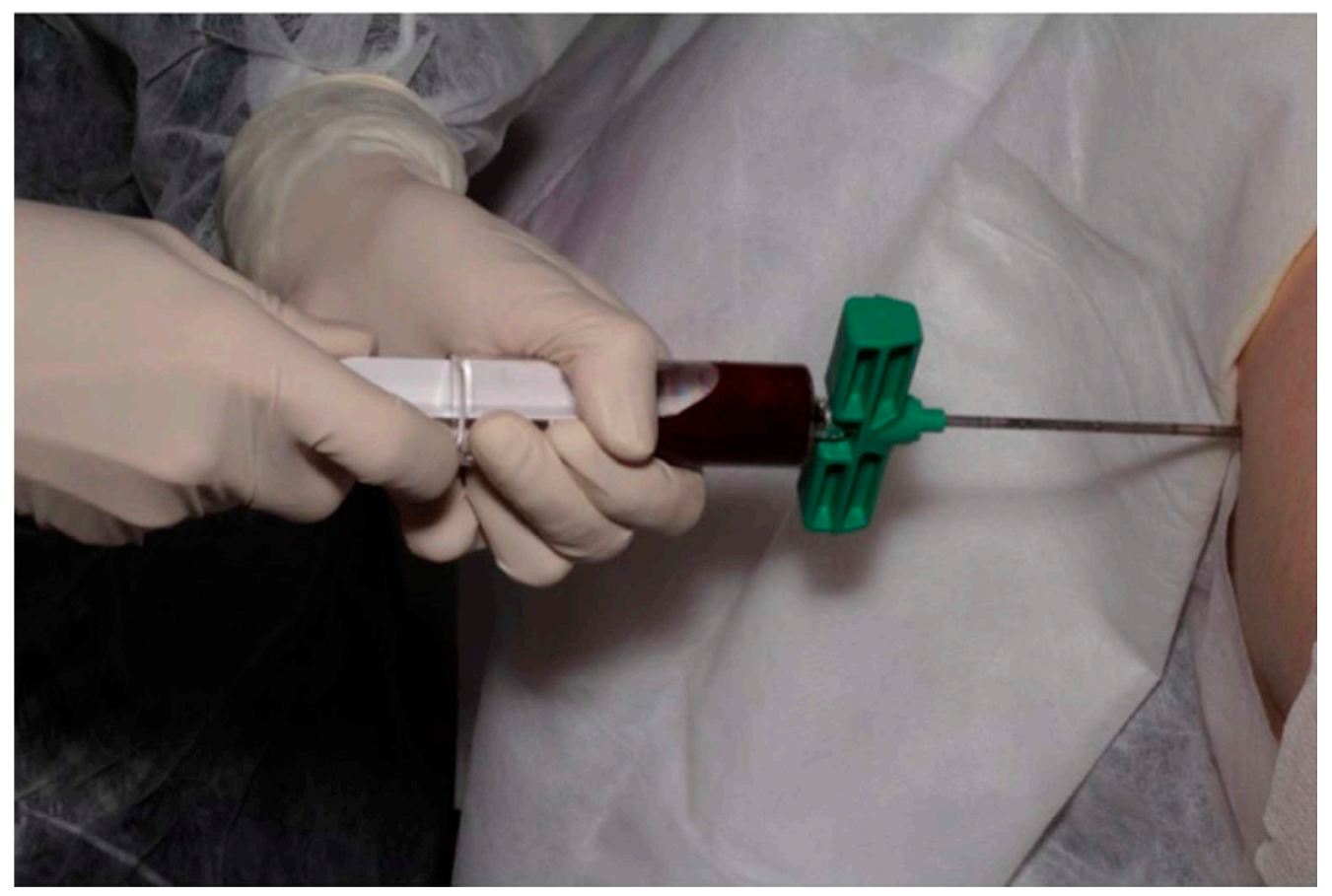

Figure 1. Puncture aspiration of bone marrow. 
The bone marrow aspirate was manipulated for bone marrow concentration using the BMAC2 kit (Terumo ${ }^{\circledR}$, São Paulo, SP, Brazil), according to the manufacturer's instructions. At the end of the procedure, $4 \mathrm{~mL}$ of bone marrow aspirate concentrate was obtained (Figure 2a,b). This process was done in all G2 G1 and G3 patients.

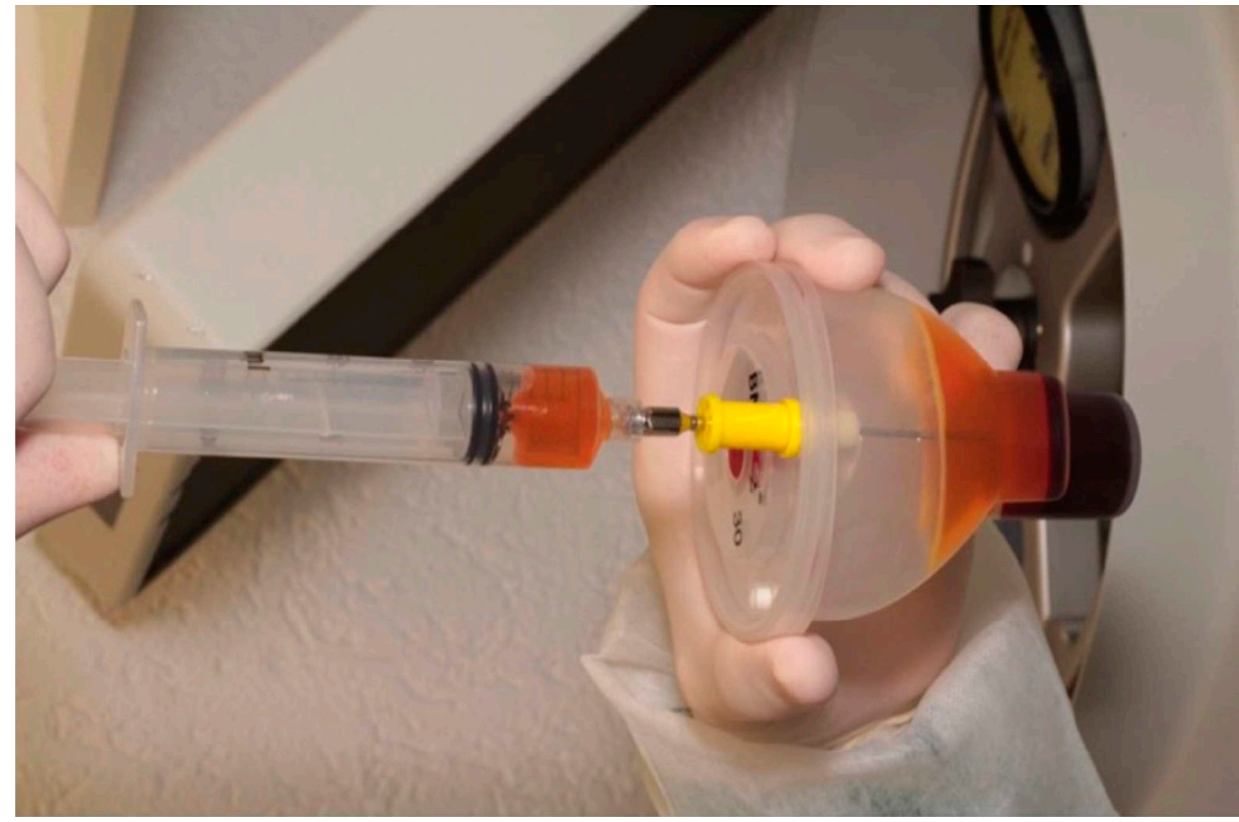

(a)

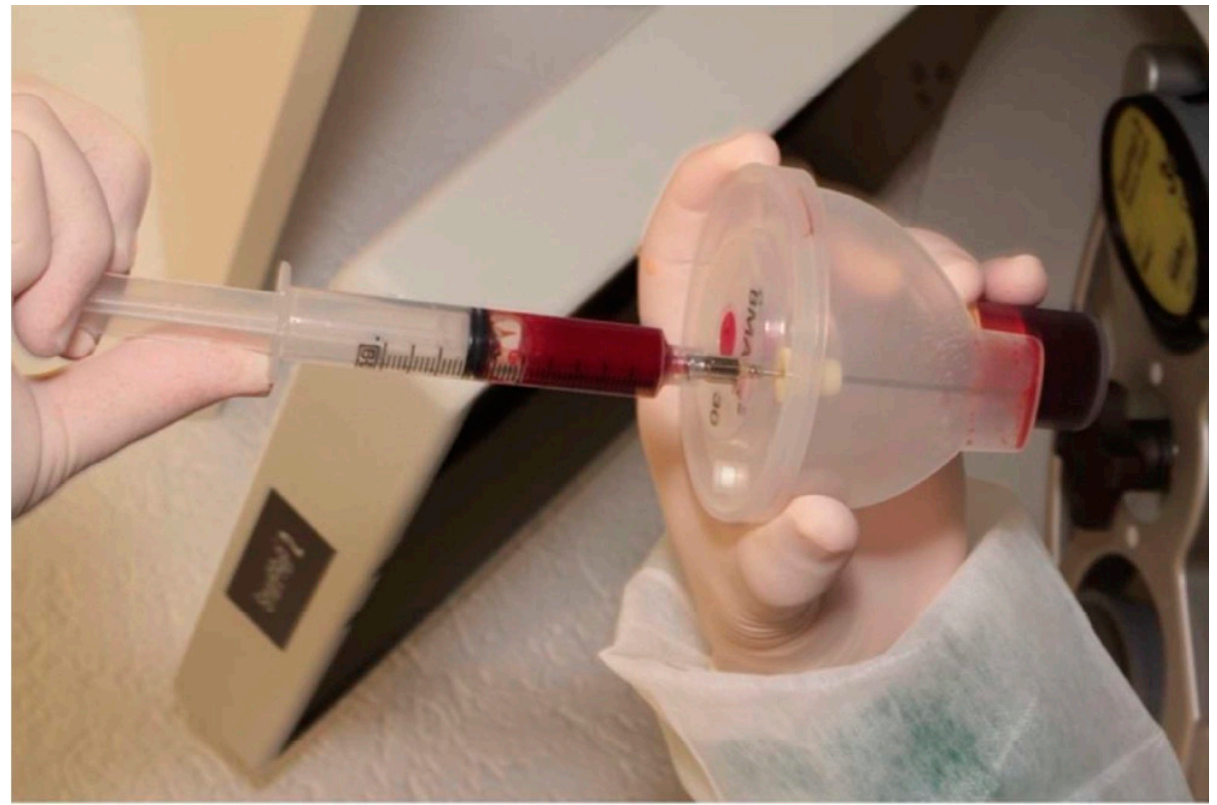

(b)

Figure 2. (a) Removal of the supernatant plasma after centrifugation. (b) Resuspension of the bone marrow aspirate concentrate (BMAC).

\subsection{Association of the Bone Marrow Aspirate Concentrate to the Xenograft Blocks}

The entire volume of BMAC was combined directly with the biomaterial by dripping until all graft material was embedded (Figure 3). This process was done in all G2 G1 and G3 G2 patients. 


\subsection{Surgical Technique for Bone Grafting}

Local infiltration and regional block anesthesia was administered, followed by an incision in the alveolar ridge to raise a mucoperiostal flap to the base of the nose to access the area to be grafted. Subsequently, the remaining bone structure was decorticated using round burs. Bone grafts $(25 \times 10 \times 5)$ from equine origin (Bioteck, Italy) were adapted and fixed onto the bony defect using one or two titanium screws (Neodent, Brazil) that measured $1.5 \mathrm{~mm}$ in diameter and 8.0 or $10.0 \mathrm{~mm}$ in length (Figures 3 and 4 ). After bone blocks fixation, they were covered by a resorbable membrane (Bioteck, Torino, Italy) and the flap was closed by using single sutures.

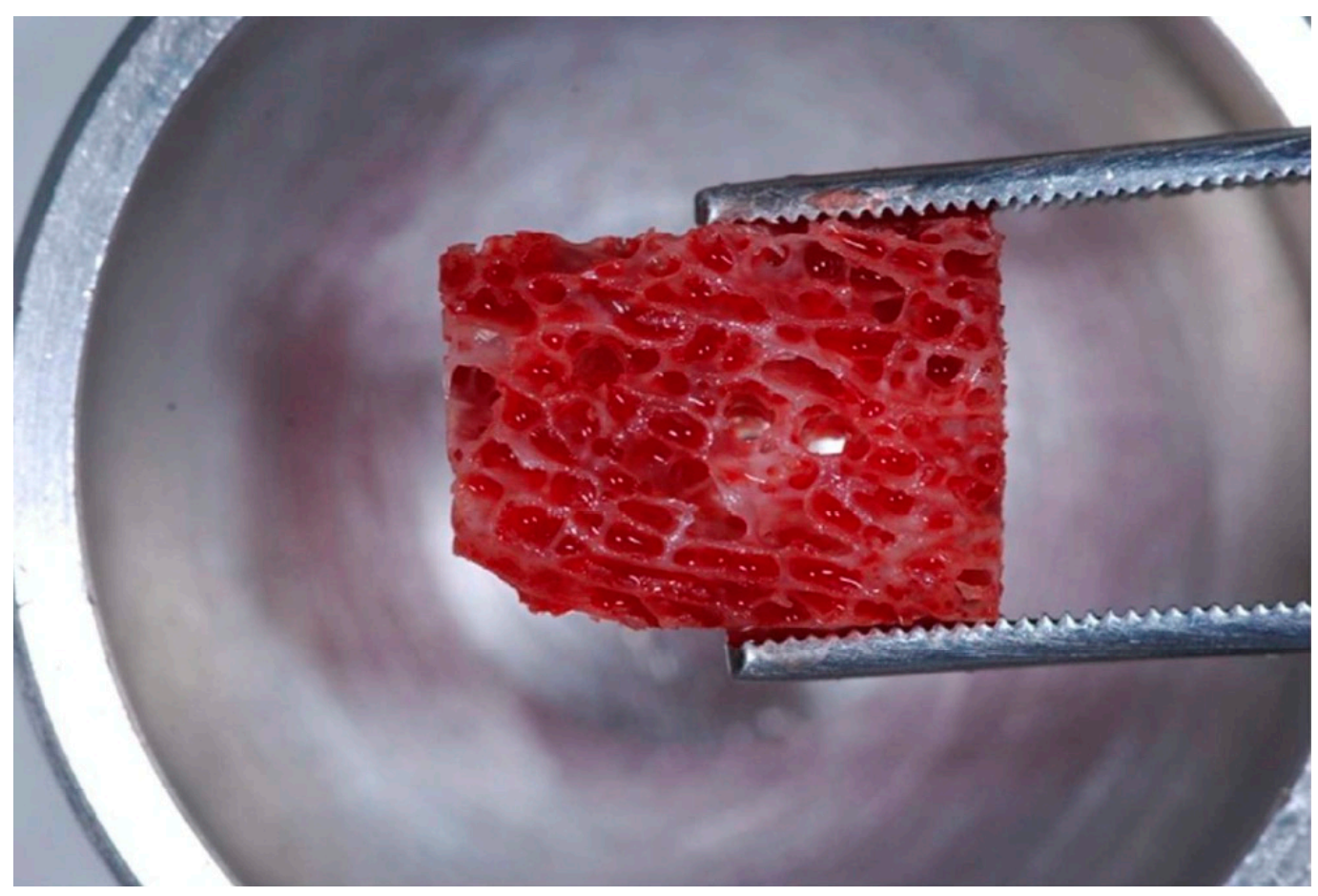

Figure 3. Xenogeneic graft block embedded in BMAC.

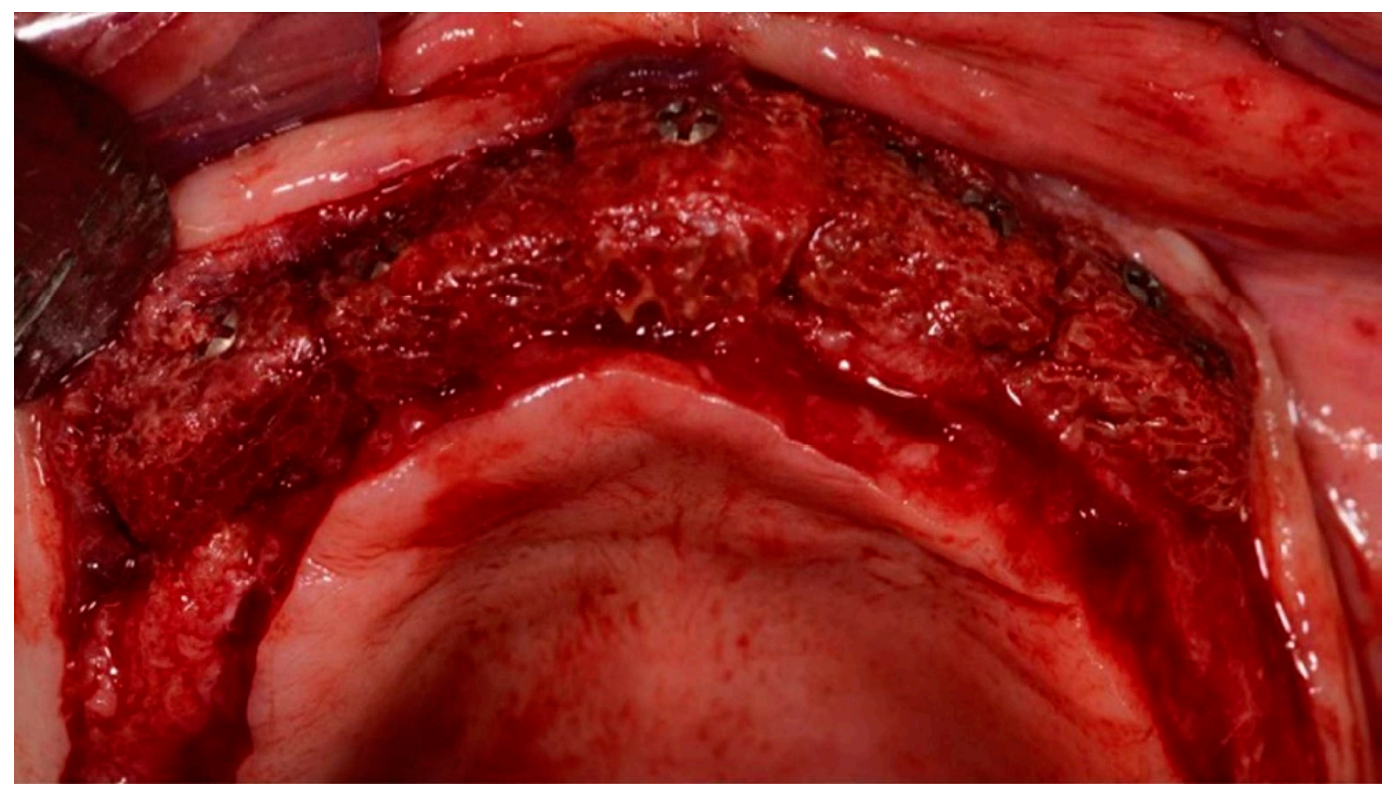

Figure 4. Blocks fixed to the receptor site. 


\subsection{Hyberbaric Oxygenation ( $\mathrm{HBO}$ )}

A specialist physician in hyperbaric medicine assessed the patients from the hyperbaric oxygenation group (G2) to ensure their safety to undergo the procedure, which occurred $24 \mathrm{~h}$ after bone grafting. The hyperbaric chamber used was a Multiplace $n^{\circ}$ 16251, model SR 10 (Ilma metalúrgica, Indaiatuba-Sao Pablo, Brazil).

Briefly, each patient was accommodated into the chamber, which was pressurized with air ( $21 \%$ oxygen) to 2.5 atmospheres ( $15 \mathrm{~m}$ deep), equivalent to $22 \mathrm{lbs}$. over approximately $12 \mathrm{~min}$, during which the patients performed the Valsalva maneuver to compensate for pressurization. After the facemask was in place, $100 \%$ oxygen was administered.

Each session of hyperbaric oxygen therapy lasted between 100 and $120 \mathrm{~min}$. During each session, patients were given oxygen on three occasions, the first lasting $20 \mathrm{~min}$, whereas the second and third for $30 \mathrm{~min}$. Patients were monitored throughout the session by a specially trained nursing technician.

Depressurization was performed gradually over $12 \mathrm{~min}$, during which patients kept their facemask on receiving 100\% oxygen until the last 3 meters of pressure. Once depressurization was complete, the chamber hatch was opened and the patient was released. In total, the patients underwent a daily session of hyperbaric oxygenation for twenty days. This process was done in every G2 patients.

\subsection{Bone Biopsies}

For all patients, after six months of grafting, the osteotomy site was reopened (Figure 5) for installation of dental implants, when bone samples were collected using a trephine drill (Figures 6 and 7), and subsequently fixed in $10 \%$ buffered formalin for histological analysis.

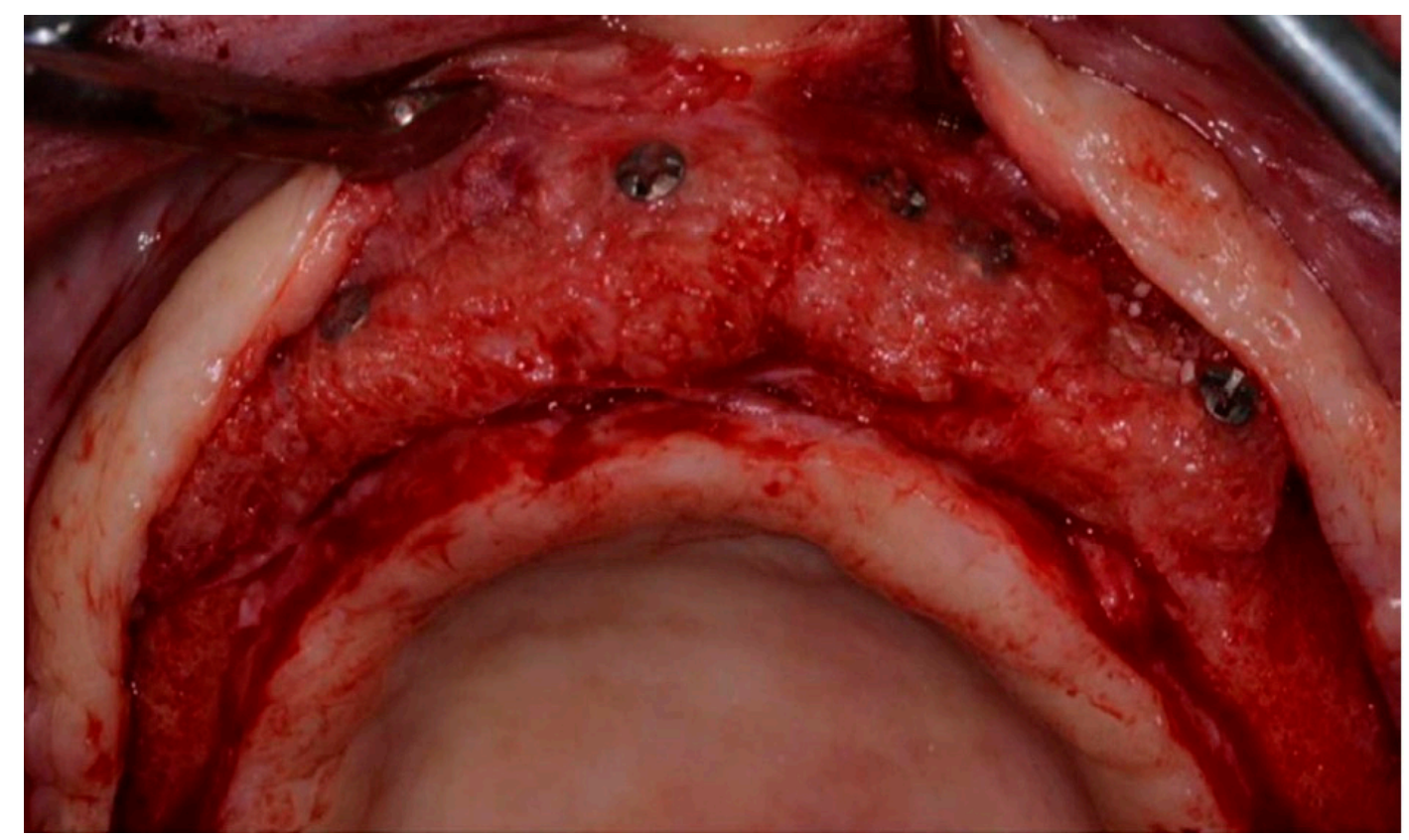

Figure 5. Second-stage surgical access 6 months postoperatively. 


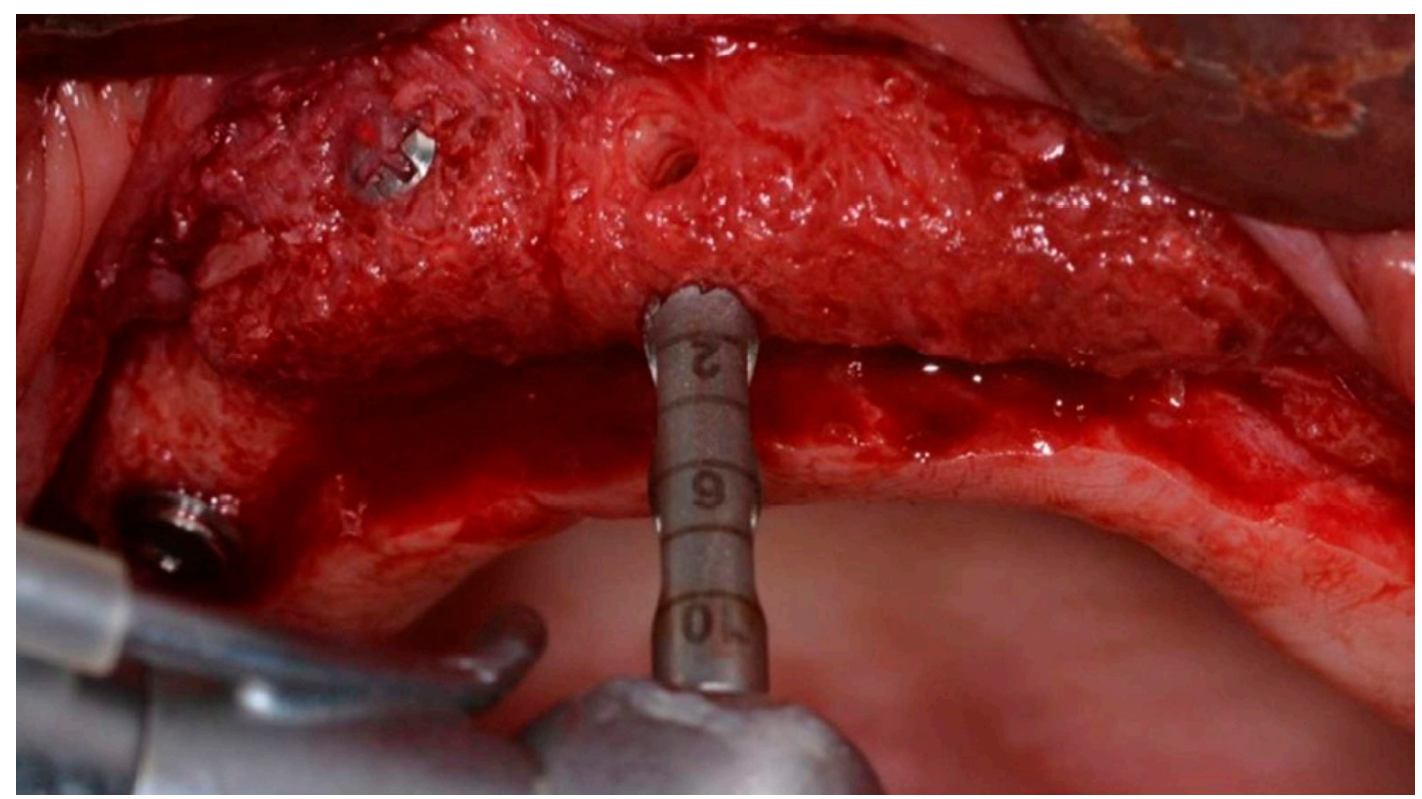

Figure 6. Trephine drill collecting samples.

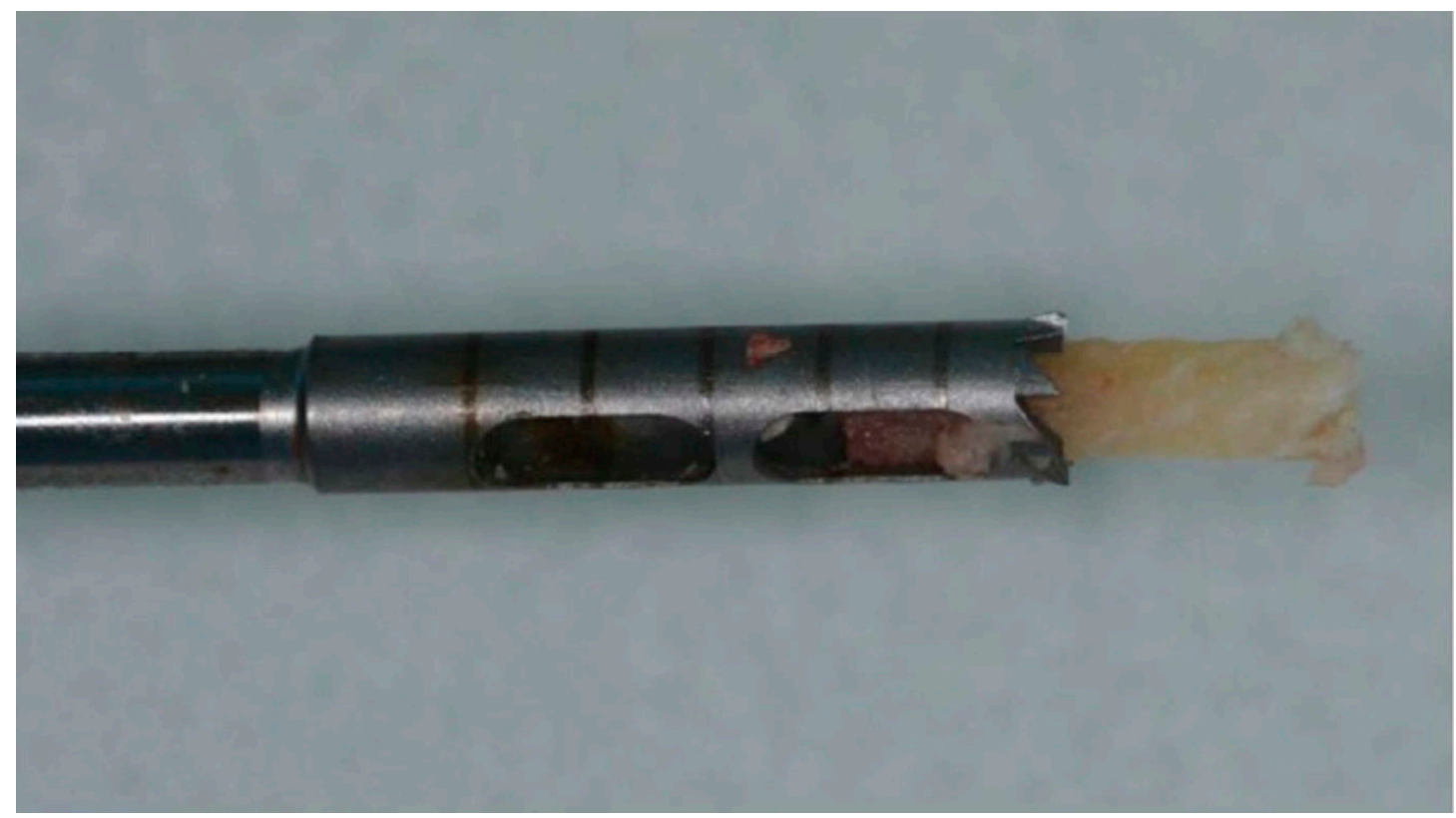

Figure 7. Bone specimen removed from the trephine core.

\subsection{Histomorphometric Evaluation}

The biopsies were fixed in $10 \%$ buffered formalin for $24 \mathrm{~h}$ and decalcified in $20 \%$ formic acid for three hours. They were then processed and embedded in paraffin. Five-micrometer sections were cut, mounted on slides and stained for Masson's trichrome. Images were captured using a Nikon Elipse Ci microscope at $100 \times$ magnification coupled to an Infinity 1 digital camera (5 megapixel) (Lumenera Co., Nepean, ON K2E 8A7 Canada), and reproduced on a computer screen using the Infinity Analyze software (Lumenera Co., Canada). Histomorphometry was performed using Image J (NIH) to quantify the areas of vital mineralized tissue (VMT), non-mineralized tissue (NMT), and non-vital mineralized tissue (NVMT) (Figures 8-10). The level of newly formed bone (i.e., VMT) was stated as the primary outcome of this study. 


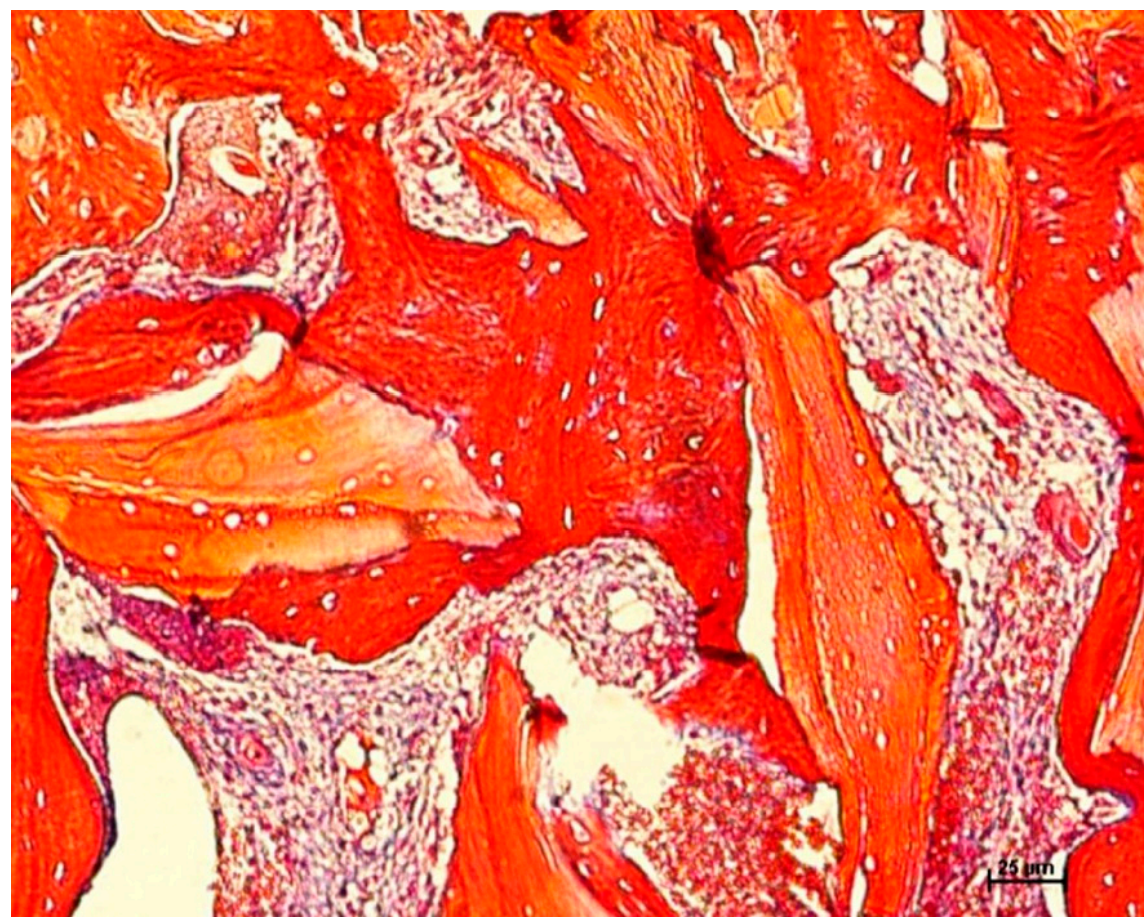

Figure 8. Histological view of non-vital mineralized tissue (NVMT) (light red), vital mineralized tissue (VMT) (dark red) and non-mineralized tissue (NMT) (sparse tissue) from a control group (CG) specimen, under $100 \times$ magnification (Masson's trichrome).

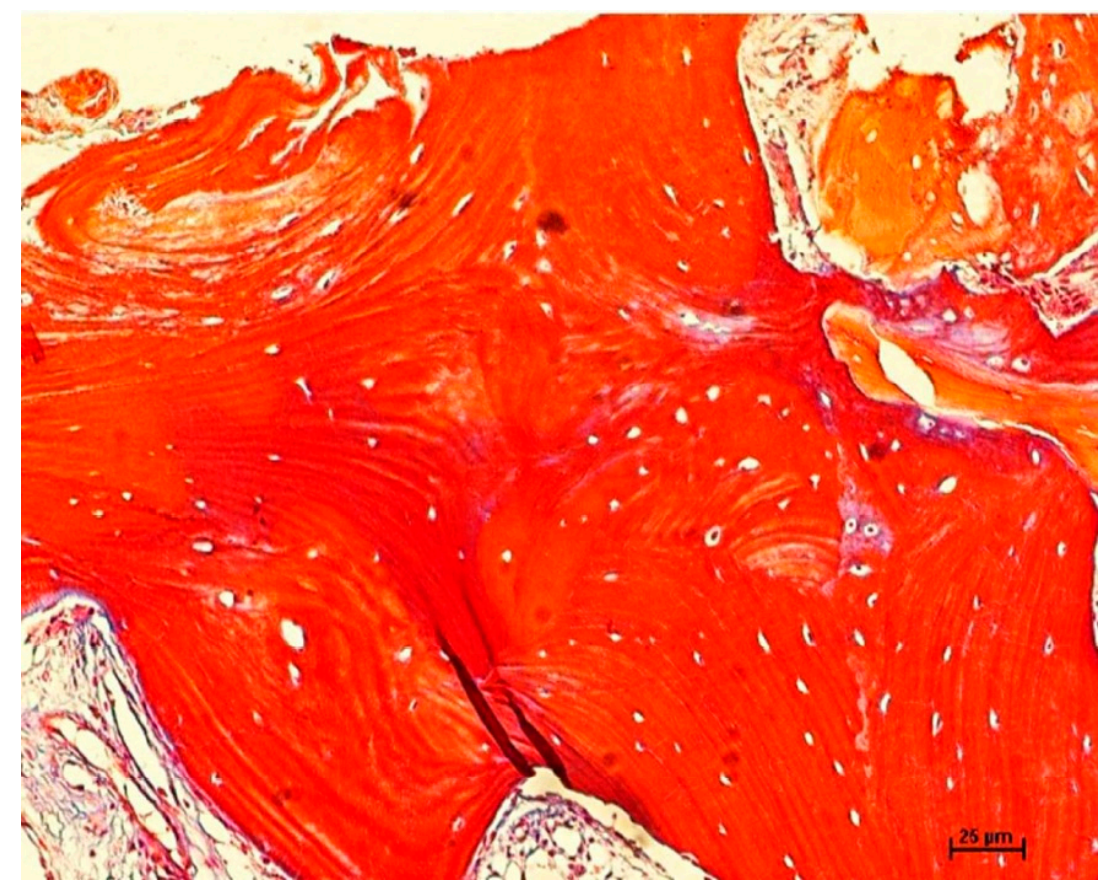

Figure 9. Histological view of NVMT (light red), VMT (dark red) and NMT (sparse tissue) from a Group 1 (G1) specimen, under $100 \times$ magnification (Masson's trichrome). 


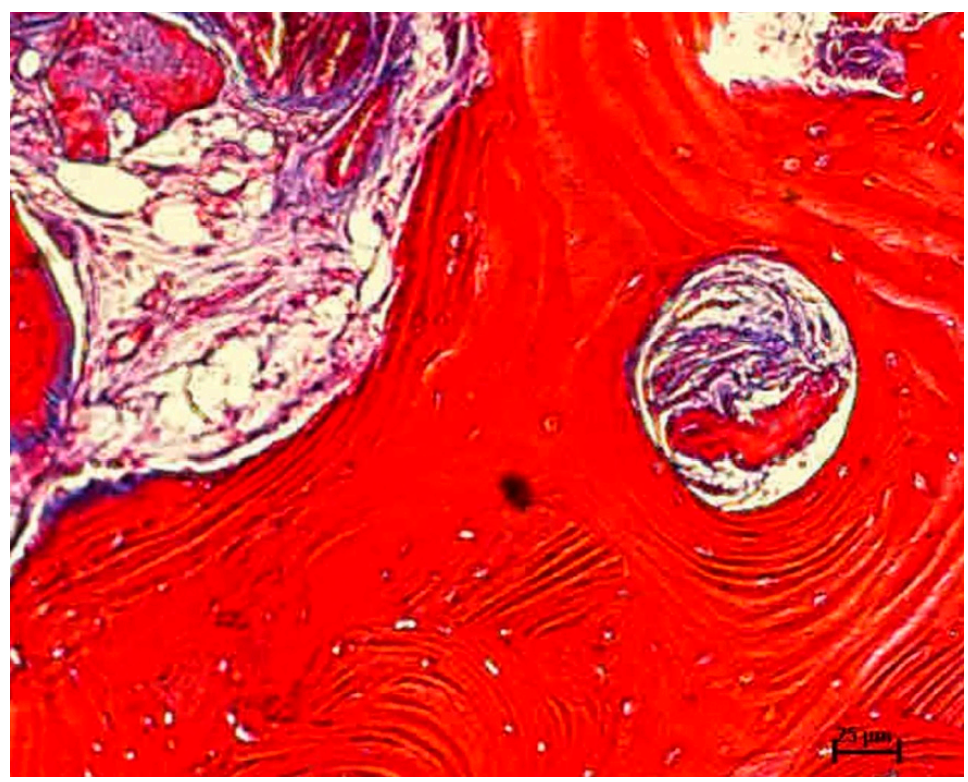

Figure 10. Histological view of NVMT (light red), VMT (dark red) and NMT (sparse tissue) from a Group 2 G2) specimen, under 100× magnification (Masson's trichrome).

\subsection{Computed Tomographic (CT) Evaluation}

Cone beam computed tomography (I-CAT Workstation, Cone Beam 3D, Imaging Sciences International Hatfield, Rochester, NY, USA) of the maxilla of all patients was performed at $1 \mathrm{~mm}$ slices on three occasions, namely T0 (preoperative), T4 (4 months after surgery), and T8 (8 months after surgery). The images obtained were analyzed using XoranCAT $^{\mathrm{TM}}$ software, version 3.1.62 (Figures 11 and 12). Alveolar bone thickness was measured between the bony crest and a $15 \mathrm{~mm}$ apical imaginary line to the bone crest, dividing the alveolar ridge into $3 \times 5 \mathrm{~mm}$ thirds: Apical, middle, and coronary (Figure 13). Bone thickness was measured from the most central point of each third. The average value from the three measurements was then considered to calculate mineralized tissue gain, from T0 through to T4 and T8. Statistical analysis was performed on bone gain at four months by subtracting the mean T0 value from the T4 value, and the same for T8 (8 months). The level of mineralized tissue gain was stated as the secondary outcome of this study.

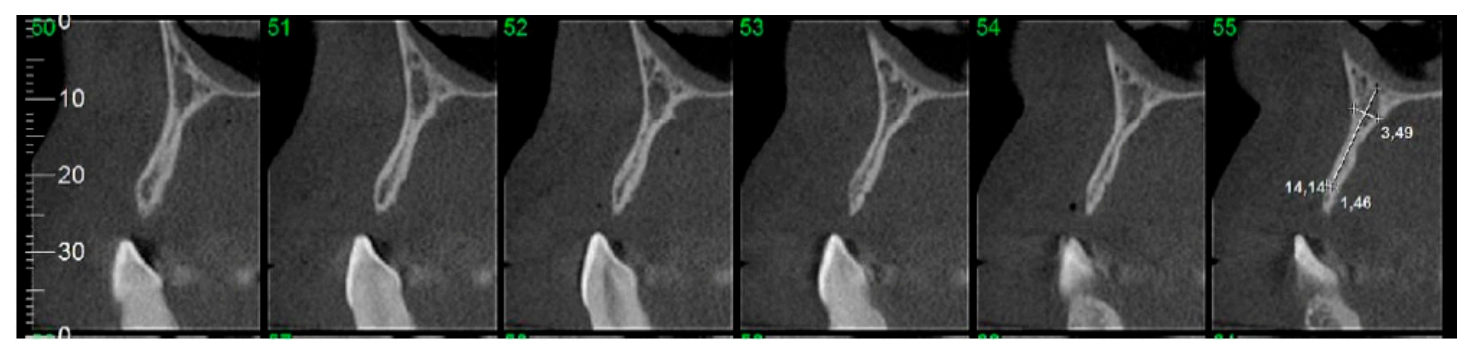

Figure 11. Preoperative parasagittal tomographic slices.

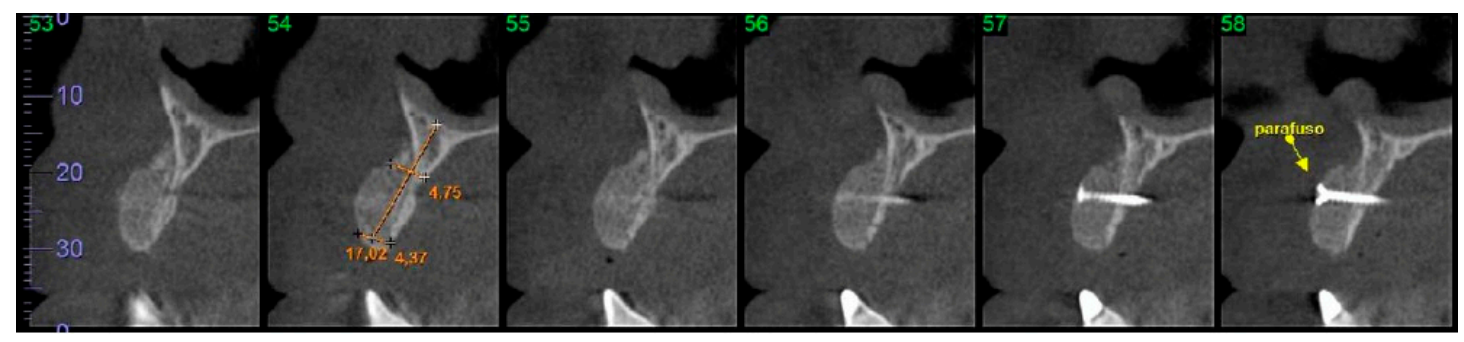

Figure 12. Postoperative parasagittal tomographic slices. 


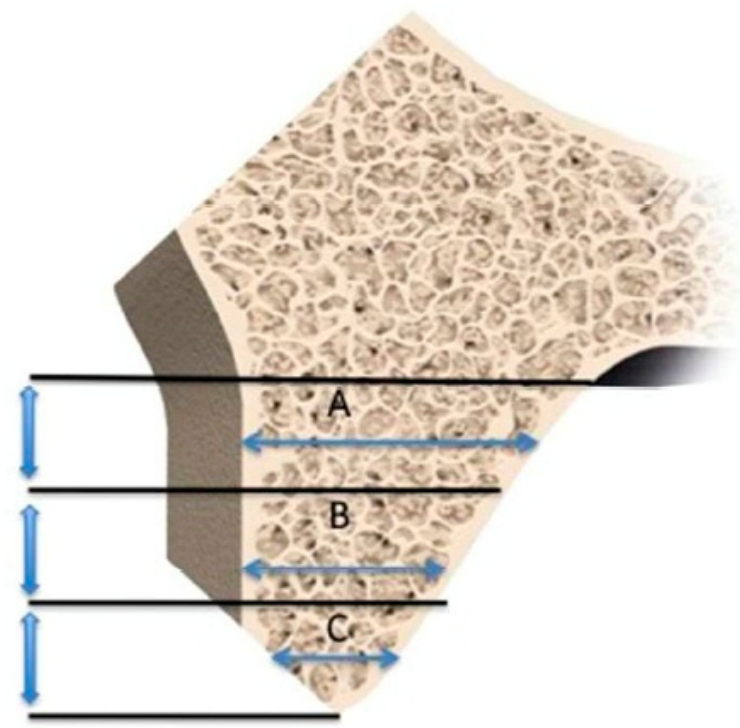

Figure 13. Schematic representation of the tomographic measurements.

\subsection{Randomization Procedure}

The patients were assigned into three groups (CG, G1, or G2) by a randomized procedure. Randomization was performed using specific software, available at http:/ /www.randomization.com//.

\subsection{Statistical Analysis}

The Kruskal-Wallis test was used to analyze all groups and when a statistical difference was verified, the Wilcoxon test was used for pairwise comparisons. Differences between mean values were analyzed on SAS (Statistical Analysis System, NC, USA) software version 9.1.3 at $p<0.05$. Post hoc sample power calculations were performed on G*Power 3.1 (University of Düsseldorf, Düsseldorf, Germany).

\section{Results}

All patients were able to receive implants and a Branemark's rehabilitation protocol. No complications were observed, neither at the recipient bed nor at the bone marrow's donor site. The histomorphometric analysis revealed that CG had the lowest percentages of VMT (36.58 $\pm 9.56 \%)$, whereas G1 and G2 showed similar levels of vital hard tissue gain $(55.64 \pm 2.83 \%$ and $55.30 \pm 1.41 \%$, respectively). The opposite effect was observed for NMT, where the highest percentages of soft tissue were recorded for CG, followed by G1 and G2, with the latter two groups showing no significant difference between each other (Table 1). A similar pattern was observed for NVMT, with highest values recorded for CG, followed by equivalent percentages between G1 and G2 (Table 1).

Table 1. Histomorphometric results in percentage (\%).

\begin{tabular}{cccc}
\hline & CG & G1 & G2 \\
\hline VMT & $36.58 \pm 9.56 \mathrm{a}$ & $55.64 \pm 2.83 \mathrm{~A}$ & $55.30 \pm 1.41 \mathrm{~A}$ \\
NMT & $51.21 \pm 11.54 \mathrm{a}$ & $39.76 \pm 10.33 \mathrm{~A}$ & $40.3 \pm 11.48 \mathrm{~A}$ \\
NVMT & $11.16 \pm 2.37 \mathrm{a}$ & $3.65 \pm 0.87 \mathrm{~A}$ & $4.10 \pm 0.41 \mathrm{~A}$ \\
\hline
\end{tabular}

CG: Control group; G1: Group bone marrow; G2: group bone marrow and hyperbaric oxygenation; VMT: vital mineralized tissue; NMT: Non-mineralized tissue and NVMT: Non-vital mineralized tissue. Values followed by different lowercase letters in the same row indicate a significant difference (Kruskal-Wallis, $p<0.05$ ). Values followed by different capital letters in the same column indicate a significant difference (Wilcoxon Mann-Whitney U test, $p<0.05)$. 
The post hoc sample power achieved in the pairwise comparisons that revealed a significant difference between groups was higher than $99.9 \%$, based on 8 patients per group (Table 2).

Table 2. Achieved power, Wilcoxon Mann-Whitney U test $(n=8)$.

\begin{tabular}{ccccc}
\hline \multirow{3}{*}{ VMT } & Effect Size & Non-Centrality Parameter $(\boldsymbol{\delta})$ & Power Achieved (\%) \\
\hline \multirow{3}{*}{ NMT } & CG vs. G1 & 2.703 & 5.283 & $99.90 *$ \\
& CG vs. G2 & 2.739 & 5.354 & $99.90^{*}$ \\
& G1 vs. G2 & 0.152 & 0.297 & 8.60 \\
\hline \multirow{3}{*}{ NVMT } & CG vs. G1 & 0.994 & 1.944 & 57.80 \\
& CG vs. G2 & 0.947 & 1.852 & 54.40 \\
& G1 vs. G2 & 0.047 & 0.091 & 5.90 \\
\hline & CG vs. G1 & 4.206 & 8.221 & $100.00 *$ \\
& CG vs. G2 & 3.954 & 7.729 & $100.00 *$ \\
\hline
\end{tabular}

High sample power ${ }^{*}$ ) found in the pairwise comparisons that reached statistical significance (critical $t=1.768$, D.F. = 13.278). CG: Control group; G1: Group bone marrow; G2: group bone marrow and hyperbaric oxygenation; VMT: vital mineralized tissue; NMT: Non-mineralized tissue and NVMT: Non-vital mineralized tissue.

The tomographic evaluation did not reveal significant differences between the groups, either at 4 months or at the 8 months postoperatively (Table 3 ).

Table 3. Mean values of bone gain in millimeters measured on CT scans.

\begin{tabular}{ccc}
\hline & 4 Months & 8 Months \\
\hline CG & $4.17 \pm 0.37 \mathrm{ab}$ & $4.01 \pm 0.86 \mathrm{ab}$ \\
G1 & $3.85 \pm 0.50 \mathrm{ab}$ & $3.83 \pm 0.27 \mathrm{ab}$ \\
G2 & $3.83 \pm 0.73 \mathrm{ab}$ & $3.57 \pm 0.49 \mathrm{ab}$
\end{tabular}

CG: Control Group; G1: Group bone marrow; G2: group bone marrow and hyperbaric oxygenation; 8 months: mean value obtained from the formula T4-T0; 8 months: mean value obtained from the formula T8-T0. Values followed by different lowercase letters on the same line indicate a significant difference (Kruskal-Wallis, $p<0.05)$. Values followed by different capital letters in the same column indicate a significant difference (Wilcoxon Mann-Whitney $\mathrm{U}$ test, $p<0.05)$.

\section{Discussion}

Teeth loss leads to alveolar bone resorption, which may hinder implant-supported dental rehabilitation. In such context, bone grafting procedures play a vital role in recovering mineralized tissue for implant anchorage, which was demonstrated in the 3 groups evaluated in the present study, where all patients were successfully rehabilitated by implant supported prosthesis. Among the options for bone grafting, autologous bone blocks are still regarded as the gold standard for volume gain, especially in areas of critical bony defects, such as those included in the present study. Autologous grafting does not elicit adverse immunological reactions; instead, it features osteoconduction, osteoinduction, and osteogenesis, which are regarded as the main positive predictive factors for graft incorporation $[16,17]$. Conversely, the morbidity associated with such an approach, as well as the limited availability of adequate donor sites, have led to an ongoing search for bone substitutes with similar characteristics [18].

Alternative biomaterials to autologous bone, whether homogenous, xenogeneic, or synthetic, are acellular, and therefore, not recognized as osteogenic. Consequently, such biomaterials alone are not as effective as autologous grafts for regenerative procedures, unless combined with potentially osteogenic factors, such as BMAC, which has been showing promising results in terms of vital bone and/or mineralized tissue gain $[19,20]$. In this context of combining biomaterials for bone reconstructions, the added benefit of hyperbaric oxygenation $(\mathrm{HBO})$ has not been reported, as far as the authors are aware. Hypothetically, an increase in neovascularization and oxygenation at the grafted site could maximize the regenerative outcome. Therefore, as BMAC has been proven useful in bone regeneration by histomorphometry analysis, G2 group was investigated in the present study to test whether 
hyperbaric oxygenation could act synergistically to BMAC producing even higher levels of neoformed bone. In this study, two methods of evaluation were used, CT exams and histomorphometric analysis.

For both postoperative follow-up evaluations concerning the CT exams (4 months and 8 months), hard tissue gain was similar between groups $(p>0.05)$. This finding corroborates the study by Pelegrine et al. (2016) [21], who demonstrated a significant gain in hard tissue, also evaluated by $\mathrm{CT}$ exams, when comparing a bone xenograft alone against the same biomaterial associated with BMAC, reporting gains of $4.34 \pm 1.58 \mathrm{~mm}$ and $4.09 \pm 1.33 \mathrm{~mm}$, respectively, 8 months postoperatively. Nissan et al. (2011) [22] also reported similar bone gain levels using homologous bone in appositional grafting. Furthermore, the preclinical trial by Pelegrine et al. (2011) [23] found no significant differences in vertical gain, when comparing homologous biomaterial (HB), HB combined with fresh bone marrow and autologous grafts. Based on the reports, the lack of significant difference between groups presented herein, concerning the appositional gain evaluated by CT exams, does not come as a surprise.

Regarding the histomorphometric analysis, significant differences were observed between CG and the two test groups (i.e., G1 and G2), though no difference was detected between G1 and G2 (Table 1). These results reiterate that the association of BMAC to a xenogeneic graft optimizes bone neoformation (VMT), though HBO did not bring any added benefit. VMT levels in the CG were equivalent to those reported by Oliveira et al. (2016) [24], who also used xenogeneic bone grafts. The superior results for the variable VMT in the groups where BMAC was used (i.e., G1 and G2), may be justified by the presence of potentially osteogenic cells and growth factors in the bone marrow, as reported by Soltan et al. (2009) [25]. The benefits of combining BMAC with a particulated xenograft, concerning new bone formation, was previously demonstrated for both inlay [26] and onlay [21] bone grafts. The levels of mineralized and non-mineralized tissue presented in the previous study of Pelegrine et al. (2016) [21], were similar with the results showed in this study.

There may be two plausible explanations for the disappointing contribution of $\mathrm{HBO}$ to VMT gain. The first is a lack of effectiveness of HBO on non-infected hard tissue, as the scientific evidence supporting a positive role of hyperbaric oxygen on healing involves mostly soft tissues in situations of extreme hypoxia [27-29]. There is evidence in the literature that HBO may be useful to treat osteomyelitis [30,31], which could somewhat dampen the strength of this first theory, though osteomyelitis is associated with intense infection, which is an altogether different scenario to guided tissue regeneration for implant supported dental rehabilitation. $\mathrm{HBO}$ has been reported as an antimicrobial approach even in cases of infected bone [32], which demonstrates its positive impact on hard tissue, though secondary to resolution of a pre-existing infectious process, as opposed to a direct impact on germ-free bone neoformation. The second theory suggested by the authors was that HBO had no effect on bone neoformation because it was associated with BMAC, which is already known to promote a significant increase in neovascularization, an aspect that might not be further enhanced by $\mathrm{HBO}$. To confirm this second theory, a fourth experimental group would have been necessary, in which the xenograft would be associated to $\mathrm{HBO}$ alone, without BMAC. If, in this case, $\mathrm{HBO}$ did maximize the results in terms of VMT, it could be concluded that it had a positive impact on bone healing.

The CG, in addition to presenting the lowest levels of VMT, had the highest levels of NMT and NVMT when compared to G1 and G2 (Table 1). This may be related to an acceleration of the healing process in groups where BMAC was used (G1 and G2), which corroborates the findings on VMT, since higher levels of bone neoformation are commonly related to higher levels of biomaterial resorption. Such histomorphometric differences between the groups, despite a lack of quantitative equivalence with the $C T$ readings, represent a qualitative superiority of groups in which BMAC was used. According to Yamada et al. (2012) [33], the quality of the regenerated tissue after 6 months of grafting may drop by $50 \%$ in terms of mechanical strength when compared to native bone, which, according to the authors, is an evidence of a more fragile tissue in which implant stability could be compromised. Therefore, though no formal mechanical strength testing was performed on the regenerated tissue in the present study, one may speculate that the presence of higher levels of vital 
mineralized tissue and lower levels of non-mineralized tissue in G1 and G2 might be surrogate markers of implant stability, which could be the focus of forthcoming research.

The sample population that composed the study groups $(n=8)$ tested herein proved to be highly robust (Table 2) for the main variable analyzed, namely histomorphometry of VMT. Larger sample populations, are therefore, unlikely to generate a different outcome for such variable and increased sample size ought to be discouraged based on the principles of bioethics of human experimentation. However, it is important to state that the follow-up of this study is short, and therefore, long-term results may be checked in the future. Despite this, it is also of major importance to state that the results presented in this paper may have important clinical implications, especially in situations of severe horizontal bone loss. In these situations, as most of the implant surface would be in contact with a newly formed tissue presented after a grafting procedure, higher amounts of vital mineralized tissue would be desirable. Therefore, the usage of BMAC would be clinically acceptable, as it can maximize bone formation. The indication of a cell therapy approach for situations of severe atrophy was weighted in a recent guideline for horizontal bone augmentation (i.e., HAC 4) [34].

As far as the authors are aware, this is the first randomized controlled trial evaluating the association of cell therapy with hyperbaric oxygenation in bone grafting for implant supported dental rehabilitation. In view of the findings presented herein, the use of bone marrow aspirate concentrate favored bone regeneration, though hyperbaric oxygenation did not provide any added benefit. However, it is important to highlight that different study designs should be considered to isolate variables to ascertain the benefit of $\mathrm{HBO}$ over BMAC.

\section{Conclusions}

Appositional bone reconstruction using block xenograft associated with bone marrow aspirate concentrate resulted in a significant increase of newformed bone than the xenograft alone, though the use of hyperbaric oxygenation did not enhance the results.

Author Contributions: Conceptualization: A.C.A.; Data Curation \& Resources: P.P.; Formal Analysis: M.S.; Funding Acquisition \& Investigation: L.G.S.d.M. and A.C.A.; Methodology: M.L.T. and P.P.; Resources \& Software: A.A.P.; Writing-original draft: A.A.P. and A.C.A.; Writing-review \& editing: P.P. and M.S.; Visualization \& Methodology: L.G.S.d.M.; Supervision: A.A.P. and J.L.C.G.

Funding: This research received no external funding.

Acknowledgments: This study was financed in part by the Coordenação de Aperfeiçoamento de Pessoal de Nível Superior-Brasil (CAPES)_Finance Code 001.

Conflicts of Interest: The authors declare that they have no conflict of interest.

\section{References}

1. Sheikh, Z.; Najeeb, S.; Khurshid, Z.; Verma, V.; Rashid, H.; Glogauer, M. Biodegradable Materials for Bone Repair and Tissue Engineering Applications. Materials 2015, 8, 5744-5794. [CrossRef] [PubMed]

2. Pistilli, R. Case of severe bone atrophy of the posterior maxilla rehabilitated with blocks of equine origin bone: Histological results. Implant Dent. 2013, 22, 8-15. [CrossRef] [PubMed]

3. Quarto, R.; Mastrogiacomo, M.; Cancedda, R.; Kutepov, S.K.; Muchechev, V.; Lavroukov, A.; Kon, E.; Maracacci, M. Repair of large bone defects with the use of autologous bone marrow stromal cells. N. Engl. J. Med. 2001, 344, 385-386. [CrossRef] [PubMed]

4. Lemoli, R.M.; Bertolini, F.; Cancedda, R.; De Luca, M.; Del Santo, A.; Ferrari, G.; Ferrari, S.; Martino, G.; Mavilio, F.; Tura, S. Stem cell plasticity: Time for a reappraisal. Haematologica 2005, 90, 360-381. [PubMed]

5. Sefat, F.; Raja, T.I.; Zafar, M.S.; Khurshid, Z.; Najeeb, S.; Zohaib, S.; Ahmadi, E.D.; Rahmati, M.; Mozafari, M. Chapter 3-Nanoengineered Biomaterials for Cartilage Repair. Nanoeng. Biomater. Regener. Med. 2019, 39-71. [CrossRef]

6. Kale, S.; Long, M.W. Osteopoiesis the early development of bone cells. Crit. Rev. Eukaryot. Gene Expr. 2000, 10, 259-271. [CrossRef] [PubMed] 
7. Yamamoto, N.; Furuya, K.; Hanada, K. Progressive development of the osteoblast phenotype during differentiation of osteoprogenitor cells derived from fetal rat calvaria: Model for in vitro bone formation. Biol. Pharm. Bull. 2002, 25, 509-515. [CrossRef] [PubMed]

8. Kaigler, D.; Krebsbach, P.H.; Polverini, P.J.; Mooney, D.J. Role of vascular endothelial growth factor in bone marrow stromal cell modulation of endothelial cells. Tissue Eng. 2003, 9, 95-103. [CrossRef] [PubMed]

9. Lucarelli, E.; Fini, M.; Beccheroni, A.; Giavaresi, G.; Di Bella, C.; Aldini, N.N.; Guzzardella, G.; Martini, L.; Cenacchi, A.; Di Maggio, N.; et al. Stromal stem cells and platelet-rich plasma improve bone allograft integration. Clin. Orthop. Relat. Res. 2005, 435, 62-68. [CrossRef]

10. Jung, Y.; Song, J.; Shiozawa, Y.; Wang, J.; Wang, Z.; Williams, B.; Havens, A.; Schneider, A.; Ge, C.; Franceschi, R.T.; et al. Hematopoietic Stem Cells Regulate Mesenchymal Stromal Cell Induction into Osteoblasts Thereby Participating in the Formation of the Stem Cell Niche. Stem Cells 2008, 26, 2042-2051. [CrossRef] [PubMed]

11. Kevy, S.V.; Jacobson, M.S. Comparison of Methods for Point of Care Preparation of Autologous Platelet Gel. J. Extra Corpor. Technol. 2004, 36, 28-35. [PubMed]

12. Hernigou, P.; Desroches, A.; Queinnec, S.; Flouzat Lachaniette, C.H.; Poignard, A.; Allain, J.; Chevallier, N.; Rouard, H. Morbidity of graft harvesting versus bone marrow aspiration in cell regenerative therapy. Int. Orthop. 2014, 38, 1855-1860. [CrossRef] [PubMed]

13. Cicciu, M. Real opportunity for the present and a forward step for the future of bone tissue engineering. J. Craniofac. Surg. 2017, 28, 592-593. [CrossRef] [PubMed]

14. García-Covarrubias, L.; Cuauhtémoc Sánchez-Rodríguez, E. Hyperbaric oxygenation therapy, basic concepts. Gac. Med. Mex. 2000, 136, 45-56. [PubMed]

15. Hong, P.; Boyd, D.; Beyea, S.D.; Bezuhly, M. Enhancement of bone consolidation in mandibular distraction osteogenesis: A contemporary review of experimental studies involving adjuvant therapies. J. Plast. Reconstr. Aesthet. Surg. 2013, 66, 883-895. [CrossRef] [PubMed]

16. Burchardt, H. The biology of bone graft repair. Clin. Orthop. Relat. Res. 1983, 174, 28-42. [CrossRef]

17. Raghoebar, G.M.; Louwerse, C.; Kalk, W.W.; Vissink, A. Morbidity of chin bone harvesting. Clin. Oral Implants Res. 2001, 12, 503-507. [CrossRef] [PubMed]

18. Boniello, R.; Gasparini, G.; D’Amato, G.; Torroni, A.; Marianetti, T.M.; Foresta, E.; Azzuni, C.; Cervelli, D.; Pelo, S. Reconstruction of severe atrophic jaws with Fresh Frized Bone Allografts: Clinical histologic and histomorphometric evaluation. Eur. Rev. Med. Pharmacol. Sci. 2013, 17, 1411-1418. [PubMed]

19. Sununliganon, L.; Peng, L.; Singhatanadgit, W.; Cheung, L.K. Osteogenic efficacy of bone marrow concentrate in rabbit maxillary sinus grafting. J. Craniomaxillofac. Surg. 2014, 42, 1753-1765. [CrossRef] [PubMed]

20. Pelegrine, A.A.; Aloise, A.C.; Zimmermann, A.; Mello e Oliveira, R.; Ferreira, L.M. Repair of critical-size bone defects using bone marrow stromal cells: A histomorphometric study in rabbit calvaria. Part I: Use of fresh bone marrow or bone marrow mononuclear fraction. Clin. Oral Implants Res. 2014, 25, 567-572. [CrossRef] [PubMed]

21. Pelegrine, A.A.; Teixeira, M.L.; Sperandio, M.; Almada, T.S.; Kahnberg, K.E.; Pasquali, P.J.; Aloise, A.C. Can bone marrow aspirate concentrate change the mineralization pattern of the anterior maxilla treated with xenografts? A preliminary study. Contemp. Clin. Dent. 2016, 7, 21-26. [CrossRef] [PubMed]

22. Nissan, J.; Mardinger, O.; Calderon, S.; Romanos, G.E.; Chaushu, G. Cancellous bone block allografts for the augmentation of the anterior atrophic maxilla. Clin. Implant Dent. Relat. Res. 2011, 13, 104-111. [CrossRef] [PubMed]

23. Pelegrine, A.A.; Sorgi da Costa, C.E.; Sendyk, W.R.; Gromatzky, A. The comparative analysis of homologous fresh frozen bone and autologous bone graft, associated or not with autologous bone marrow, in rabbit calvaria: A clinical and histomorphometric study. Cell Tissue Bank. 2011, 12, 171-184. [CrossRef] [PubMed]

24. Oliveira, T.A.; Aloise, A.C.; Orosz, J.E.; de Mello e Oliveira, R.; Carvalho, P.; Pelegrine, A.A. Double Centrifugation Versus Single Centrifugation of Bone Marrow Aspirate Concentrate in Sinus Floor Elevation: A Pilot Study. Int. J. Oral Maxillofac. Implants 2016, 31, 216-222. [CrossRef] [PubMed]

25. Soltan, M.; Smiler, D.; Choi, J. Bone marrow: Orchestrated cells, cytokines, and growth factors for bone regeneration. Implant Dent. 2009, 18, 132-141. [CrossRef] [PubMed]

26. Rickert, D.; Sauerbier, S.; Nagursky, H.; Menne, D.; Vissink, A.; Raghoebar, G.M. Maxillary sinus floor elevation with bovine bone mineral combined with either autogenous bone or autogenous stem cells: A prospective randomized clinical trial. Clin. Oral Implants Res. 2011, 22, 251-258. [CrossRef] [PubMed] 
27. Haapanemi, T.; Sirsjö, A.; Nylander, G.; Larsson, J. Hyperbaric oxygen treatment attenuates glutathione depletion and improves metabolic restitution in postischemic skeletal muscle. Free Radic. Res. 1995, 23, 91-101. [CrossRef]

28. Korhonen, K.; Hirn, M.; Niinikoski, J. Hyperbaric oxygen in the treatment of Fournier's gangrene. Eur. J. Surg. 1998, 164, 251-255. [CrossRef] [PubMed]

29. Mindrup, S.R.; Kealey, G.P.; Fallon, B. Hyperbaric oxygen for the treatment of Fournier's gangrene. J. Urol. 2005, 173, 1975-1977. [CrossRef] [PubMed]

30. Rose, D. Hyperbaric oxygen therapy for chronic refractory osteomyelitis. Am. Fam. Physician 2012, 86, 888. [PubMed]

31. Delasotta, L.A.; Hanflik, A.; Bicking, G.; Mannella, W.J. Hyperbaric oxygen for osteomyelitis in a compromised host. Open Orthop. J. 2013, 7, 114-117. [CrossRef] [PubMed]

32. Goerger, E.; Honnorat, E.; Savini, H.; Coulange, M.; Bergmann, E.; Simon, F.; Seng, P.; Stein, A. Anti-infective therapy without antimicrobials: Apparent successful treatment of multidrug resistant osteomyelitis with hyperbaric oxygen therapy. IDCases 2016, 6, 60-64. [CrossRef] [PubMed]

33. Yamada, Y.; Sato, S.; Yagi, H.; Ujiie, H.; Ezawa, S.; Ito, K. Correlation in the densities of augmented and existing bone in guided bone augmentation. Clin. Oral Implants Res. 2012, 23, 837-845. [CrossRef] [PubMed]

34. Pelegrine, A.A.; Romito, G.; Villar, C.C.; Macedo, L.G.S.; Teixeira, M.L.; Aloise, A.C.; Moy, P.K. Horizontal bone reconstruction on sites with different amounts of native bone: A retrospective study. Braz. Oral Res. 2018, 32, e21. [CrossRef] [PubMed]

(C) 2018 by the authors. Licensee MDPI, Basel, Switzerland. This article is an open access article distributed under the terms and conditions of the Creative Commons Attribution (CC BY) license (http:/ / creativecommons.org/licenses/by/4.0/). 